\title{
Core allocations in co-investment problems
}

\author{
Josep Maria Izquierdo
}

Carlos Rafels

Departament de Matemàtica Econòmica, Financera i Actuarial

Universitat de Barcelona

\begin{abstract}
In a co-investment problem a set of agents face a surplus-sharing situation with a single input and a single output exhibiting increasing average returns. All agents contribute their respective inputs and expect part of the collective output. Focusing on the core of the problem, we analyze whether a core allocation of the output is acceptable or compatible with a variation on input contributions, where larger payoffs are expected by those agents whose contribution is increased. We state a necessary and sufficient condition for a core allocation to be acceptable. We also introduce and study the acceptable core, that is, those core allocations acceptable with respect to any possible increase of inputs. Finally we axiomatically characterize when a set-solution that contains acceptable core allocations shrinks into the proportional allocation.
\end{abstract}

Keywords Core $\cdot$ incentive monotonicity $\cdot$ co-investment problem $\cdot$ proportional solution

The authors acknowledge support from research grant ECO2017-86481-P (Spanish Ministry of Science and Innovation, AEI and FEDER, UE) and 2017SGR778 (Government of Catalonia). 


\section{Introduction}

In many economic and social situations agents cooperate exerting some level of effort in order to obtain a common profit. The implication of each participant in the joint project depends on the payoff agents expect to receive. The negotiation process determines the level of effort and the allocation of the total gain.

\subsection{Co-investment problems}

General co-investment problems are situations where a set of agents pool their resources to obtain a surplus. In these problems, the effort of an agent is represented by the corresponding resource contribution and the common profit is the surplus obtained. Examples of these situations are the joint investment in infrastructures by the operators in the telecommunication sector (see Bourreau et al., 2012 and 2018), cooperation at the supply chain level between firms (see Kogan and Tapiero, 2012), or the fast and recent development in the last years of private equity PE funds that collect capital from investors who act as limited partners (LPs). On the behalf of their LPs, PE funds select portfolio companies (PCs) in which they invest capital and retain them with the aim of increasing their value during a limited period, after which they exit. The literature on this topic is reviewed in Tykvov (2018) and interesting aspects of the evolution of these funds are referred in Khavul and Deeds (2016). In this paper we propose a theoretical model of co-investment that is mainly address, but not only, to financial applications. We analyze cooperative investment situations where a group of agents, each of them endowed with a certain amount of capital, has the opportunity to jointly invest them in order to obtain higher rewards. Specifically, we assume the returns are given by a function that exhibits increasing average returns and facilitates the stability of cooperation.

However, this cooperation gives rise the question of how allocate profits among the agents. One way of providing agents with incentives to cooperate is to guarantee that the payoff that each of them will receive, will be larger than the individual gain each participant might obtain acting alone. However, this might not be enough to convince agents to fully cooperate since sub-coalitions of agents could also evaluate whether the aggregate payoff received by their members compensate the joint effort exerted by them. Thus, a necessary condition for a sub-coalition to fully cooperate is to propose to its members an allocation that guarantees a joint payoff larger than the profit the sub-coalition can obtain by itself. In the economic literature (see Telser, 1994), and specifically in the field of cooperative game theory, the above argument requires the allocation to be in the core of the problem. This is a stability principle. Another reasonable principle is the following: any eventual increase in the effort exerted by each individual of a group of agents should be rewarded with a strictly higher payoff. This is an incentive principle based on the economic criterion that no agent will accept any redistribution of wealth that worsens his initial position. With the aim of characterizing allocation rules, related incentive properties are considered in Friedman (2004), for surplus sharing problems, and in Casajus et al. (2014), applied to cooperative games. Friedman (2004) names the incentive property as demand monotonicity. There are three main differences between this property and the concept 
used in our paper. First, the definition of demand monotonicity applies to single-valued solutions (or rules), while in our model we use monotonicity to test and validate arbitrary core allocations. Second, Friedmans concept of monotonicity considers the effects of an input increase by only one agent(ceteris paribus). Finally, the payoff to this agent must weakly increase, and not strictly increase as in our model. Casajus et al. (2014) introduce the concept of weak-monotonicity to characterize the egalitarian Shapley value for cooperative games. According to weak-monotonicity, a players payoff weakly increases whenever her marginal contribution and the grand coalition worth weakly increase. If we interpret our model as a cooperative $g$ ame, weak-monotonicity refers to the case when only one agent increases her input contribution.

The aim of our paper is to overlap the two principles to test the fairness and robustness of core allocations in a specific model of cooperation;the co-investment problems. Coinvestment problems were introduced as a cooperative game in Izquierdo and Rafels (1996 and 2001). In these papers it is proved the non -emptiness of the core and its coincidence with some different bargaining sets. Some economic extensions of this economic model were developed in Borm et al. (2001), De Waegenaere et al. (2005) and Gulick et al. (2010).

In Borm et al. (2001) the authors introduced the dependence of the rate of return on a deposit on, its term, the capital or both. Generically, they name these situations as deposit games and, basically, they analyze whether a deposit game becomes balanced (i.e. with a non-empty core). In our model we assume this fact since investing more to receive the same worsens this agent.

The other two papers analyze profit allocations where investors can select different investment projects to meet capital requirements for long term investment problems. Furthermore, investors may reinvest intertemporal gains from existing projects into new projects. Stable profit schemes are analyzed by using linear programming techniques.

\subsection{An explanatory example}

In this paper, we focus on a subset of the core of co-investment problems that we name the acceptable core. Let us illustrate this concept through an example. Consider three individuals having respectively $\$ 1000, \$ 1000$ and $\$ 2000$ to invest for this year. Suppose one-year deposits earn $2 \%$ interest per year if the capital deposited is strictly smaller than $\$ 3000$ euros and 4\% interest per year in other case. Investing their money separately, any individual would obtain the $2 \%$ of interest; this way, both person 1 and 2 would get $\$ 20$ and person 3 would get $\$ 40$. Pooling all their savings, individuals can jointly obtain the $4 \%$ of interest resulting in a total reward of $\$ 160$. From the individual point of view, any allocation of the $\$ 160$ should assign the first and second person a payoff larger than $\$ 20$ euros and the third person a payoff larger than $\$ 40$. However, the stability principle extends this requirement to two-person groups of individuals. For instance, if person 2 and person 3 jointly invest their savings, they can get $4 \%$ and a potential joint gain of 120 euros. The same analysis applies to the group of agents 1 and 3 with a joint potential gain of 120. However, the joint capital of the group formed by person 1 and 2 does not reach the threshold of $\$ 3000$ and thus the potential coalitional gain is just the sum of 
individual gains, $\$ 20+\$ 20=\$ 40$. The core of the problem is formed by those allocations that provide each one-person and each two-person groups a joint payoff larger than the corresponding potential gains. There are many allocations that satisfy the stability or core principle. For instance, if we give $\$ 30$ to persons 1 and 2 and $\$ 100$ to person 3, that is, if we take the allocation $(30,30,100)$ it is easy to check that stability or core conditions are all satisfied. The question is whether this allocation $(30,30,100)$ is compatible with other related deposit problems where the interest structure is the same, but capital contributions are different. Consider a different deposit problem, with same interest rate structure, but now the capitals invested are $\$ 2000$ by person $1, \$ 1000$ by person 2 and $\$ 2100$ by person 3 . In this new situation only persons 1 and 3 have increased their investment. It is easy to check the total gain is $\$ 204$ and the unique core allocation is $(80,40,84)$ (see Proposition 1). Notice that in this case, in spite of having increased the capital contribution, the payoff to person 3 must necessarily decrease if we want to preserve stability. The stability principle and the incentive principle come into conflict. In this case we say that $(30,30,100)$ is not acceptable.

\subsection{Contributions and results}

The acceptable core contains those core allocations that are consistent with both the stability and incentive principles: if some agents increase their contribution, it is possible to reward these agents with an ext ra payoff without breaking the stability of the allocation. Consequently, the originality of our approach is to discriminate between core allocations using an incentive principle. So far, to the best of our knowledge, no such discrimination has been used before. The main results of the paper are the following. We begin showing that the proportional allocation is always an acceptable core allocation (see Proposition 3 ). However, Example 2 reveals that the acceptable core might contain multiple allocations and also illustrates that the core can be strictly larger than the acceptable core. After this preliminary analysis, we deal with two interesting questions. First, given an arbitrary co-investment problem, which is the set of all acceptable core allocations? Second, under what conditions can we guarantee the coincidence of both the acceptable core and the core? The first question is addressed by Theorem 1 and Proposition 2 of Section 3. In Theorem 1 we characterize when a core allocation can sustain the incentive principle. In addition, Proposition 2 studies the interesting situation where exactly only one agent increases the input contribution. The answer to the second question about the coincidence of the core and the acceptable core is addressed in Proposition 4 of Section 4. It states that the convexity of the output function it is enough to guarantee that coincidence. The interpretation of this result is that, as long as an allocation is in the core of a convex coinvestment problem, any increase in the in vestment level can be always encouraged. In Section 5, Theorem 2, we analyze which are the properties that restrict the subset of admissible allocations to contain just the proportional one. If we add to stability and to the incentive principle, the property of core invariance (if two co-investment problems have the same core, then admissible allocations are the same), then the unique possibility is to pick out the proportional allocation. 


\section{Preliminaries}

Given $N=\{1,2, \ldots, n\}$, we denote ${ }^{1}$ by $\mathbb{R}^{N}$ the $n$-dimensional space whose components are indexed by $N$. Moreover, let $\mathbb{R}_{+}^{N}$ and $\mathbb{R}_{++}^{N}$, stands for the space of non-negative and positive vectors in $\mathbb{R}^{N}$, respectively. Given a non-empty coalition $S \subseteq N$ and a vector $x \in \mathbb{R}^{N}$, we denote $x_{S}=\sum_{i \in S} x_{i}$, being $x_{\varnothing}=0$. Furthermore, given two vectors $x, y \in \mathbb{R}^{N}$ we denote by $x \leq y$ the case where $x_{i} \leq y_{i}$, for all $i \in N$.

A co-investment problem is represented by a triplet $(N, f, \omega)$ where $N=\{1,2, \ldots, n\}$, $n \geq 2$, is the set of agents, $\omega=\left(\omega_{1}, \omega_{2}, \ldots, \omega_{n}\right) \in \mathbb{R}_{++}^{N}$ is the vector of resource endowments, where $\omega_{i}$ is the amount of resource owned by agent $i \in N$, and the function $f: \mathbb{R}_{+} \rightarrow \mathbb{R}_{+}$represents the technology that transforms $x$ units of input into $f(x)$ units of output, with the following assumptions:

$$
\begin{aligned}
& \text { (a) } f(0)=0 \text { and } f\left(\omega_{N}\right)>0 \\
& \text { (b) for any } 0<z_{1} \leq z_{2} \text { then } \frac{f\left(z_{1}\right)}{z_{1}} \leq \frac{f\left(z_{2}\right)}{z_{2}} \text {. }
\end{aligned}
$$

Condition (a) states that no output can be produced with no input contribution and that some output is produced if all agents contribute. Condition (b) formalizes the classical idea of increasing average returns. We emphasize that neither continuity nor convexity are assumed in our model; in fact in some examples we will use step-wise functions with discontinuities. As a consequence of (a) and (b) we have that $f$ is a monotonic increasing function, being strictly monotonic in the positive range. Indeed, if $0<x_{1}<x_{2}$, then by (1), $f\left(x_{1}\right) \leq \frac{x_{1}}{x_{2}} f\left(x_{2}\right) \leq f\left(x_{2}\right)$; if $f\left(x_{1}\right)>0$, then it follows that $f\left(x_{1}\right)<f\left(x_{2}\right)$.

The problem to solve is how to distribute the output $f\left(\omega_{N}\right)$ among the members of $N$. An allocation of $f\left(\omega_{N}\right)$ is denoted by a vector $x=\left(x_{1}, x_{2}, \ldots, x_{n}\right) \in \mathbb{R}^{N}$, where $x_{i}$ with $i \in N$, is interpreted as the allocation of agent $i \in N$, satisfying $x_{N}=f\left(\omega_{N}\right)$. In this case we say vector $x$ satisfies efficiency. The core of a co-investment problem $(N, f, \omega)$ is defined as

$$
C(N, f, \omega):=\left\{x \in \mathbb{R}^{N} \mid x_{S} \geq f\left(\omega_{S}\right), \text { for all } S \subseteq N, \text { and } x_{N}=f\left(\omega_{N}\right)\right\} .
$$

It coincides with the classical definition of the core of a cooperative game. It is easy to check from condition (1) that the proportional allocation with respect to the initial endowments of input is always a core element, that is, $P(N, f, \omega)=\left(P_{i}(N, f, \omega)\right)_{i \in N} \in$ $C(N, f, \omega)$, where

$$
P_{i}(N, f, \omega):=\omega_{i} \cdot \frac{f\left(\sum_{i \in N} \omega_{i}\right)}{\sum_{i \in N} \omega_{i}}, \text { for all } i \in N .
$$

At the proportional allocation, the return per unit contributed is constant and so different amounts of input receive the same average return. However, the core of a coinvestment problem is in general wider than the proportional allocation. Next proposition reveals when this happens since it states a necessary and sufficient condition to reduce the core into a singleton. Basically, the condition says that the average return of all $n-1$ person coalitions is the same as the average return for the grand coalition.

\footnotetext{
${ }^{1}$ We identify any real value function $x \in \mathbb{R}^{N}$ on $N$ with the n-tuple $x=\left(x_{1}, x_{2}, \ldots, x_{n}\right) \in \mathbb{R}^{n}$ of real numbers. See Driessen (1988).
} 
Proposition 1 For any co-investment problem $(N, f, \omega)$ the following statements are equivalent.

$$
\begin{aligned}
& \text { (1) } C(N, f, \omega)=\{P(N, f, \omega)\} . \\
& \text { (2) } \frac{f\left(\omega_{N \backslash\{1\}}\right)}{\omega_{N \backslash\{1\}}}=\frac{f\left(\omega_{N \backslash\{2\}}\right)}{\omega_{N \backslash\{2\}}}=\cdots=\frac{f\left(\omega_{N \backslash\{n\}}\right)}{\omega_{N \backslash\{n\}}}=\frac{f\left(\omega_{N}\right)}{\omega_{N}} \text {. }
\end{aligned}
$$

Proof $(1) \rightarrow(2)$. For any agent $i \in N$ we define the allocation $x^{i}=\left(x_{k}^{i}\right)_{k \in N} \in \mathbb{R}^{N}$ as follows:

$$
\begin{aligned}
& x_{i}^{i}=f\left(\omega_{N}\right)-f\left(\omega_{N \backslash\{i\}}\right), \text { and } \\
& x_{k}^{i}=\omega_{k} \cdot \frac{f\left(\omega_{N \backslash\{i\}}\right)}{\omega_{N \backslash\{i\}}}, \text { for all } k \in N \backslash\{i\} .
\end{aligned}
$$

We claim that vector $x^{i}$, for each $i \in N$, is a core allocation, $x^{i} \in C(N, f, \omega)$. It is efficient

$$
x_{N}^{i}=f\left(\omega_{N}\right)-f\left(\omega_{N \backslash\{i\}}\right)+\omega_{N \backslash\{i\}} \cdot \frac{f\left(\omega_{N \backslash\{i\}}\right)}{\omega_{N \backslash\{i\}}}=f\left(\omega_{N}\right) .
$$

Moreover, let $S \subseteq N$ be an arbitrary coalition of $N$. If agent $i \notin S$ then, by (1),

$$
x_{S}^{i}=\omega_{S} \cdot \frac{f\left(\omega_{N \backslash\{i\}}\right)}{\omega_{N \backslash\{i\}}} \geq f\left(\omega_{S}\right) .
$$

If agent $i \in S$ then

$$
\begin{aligned}
x_{S}^{i} & =f\left(\omega_{N}\right)-f\left(\omega_{N \backslash\{i\}}\right)+\omega_{S \backslash\{i\}} \cdot \frac{f\left(\omega_{N \backslash\{i\}}\right)}{\omega_{N \backslash\{i\}}} \\
& =f\left(\omega_{N}\right)-f\left(\omega_{N \backslash\{i\}}\right) \cdot \frac{\omega_{N \backslash\{i\}}}{\omega_{N \backslash\{i\}}}+\omega_{S \backslash\{i\}} \cdot \frac{f\left(\omega_{N \backslash\{i\}}\right)}{\omega_{N \backslash\{i\}}} \\
& =\omega_{N} \cdot \frac{f\left(\omega_{N}\right)}{\omega_{N}}-\omega_{N \backslash S} \cdot \frac{f\left(\omega_{N \backslash\{i\}}\right)}{\omega_{N \backslash\{i\}}} \geq \omega_{N} \cdot \frac{f\left(\omega_{N}\right)}{\omega_{N}}-\omega_{N \backslash S} \cdot \frac{f\left(\omega_{N}\right)}{\omega_{N}} \\
& =\omega_{S} \cdot \frac{f\left(\omega_{N}\right)}{\omega_{N}} \geq f\left(\omega_{S}\right),
\end{aligned}
$$

where all the inequalities come from (1). As a consequence of the above claim we obtain the implication we want to prove since, if $C(N, f, \omega)=\{P(N, f, \omega)\}$, then for any agent $i \in N, x^{i}=P(N, f, \omega)$ or equivalently $\frac{f\left(\omega_{N \backslash\{i\}}\right)}{\omega_{N \backslash\{i\}}}=\frac{f\left(\omega_{N}\right)}{\omega_{N}}$.

$(2) \rightarrow(1)$. It is known that for any arbitrary core element $x \in C(N, f, \omega)$ the payoff to any agent $i \in N, x_{i}$, is bounded above by its corresponding marginal contribution ${ }^{2}$, i.e.

\footnotetext{
2 The marginal contribution of an agent $i \in N$ measures the effect on the total output of adding agent $i$, i.e. $f\left(\omega_{N}\right)-f\left(\omega_{N \backslash\{i\}}\right)$. It is easy to check that for any core element $x \in C(N, f, \omega)$, the payoff $x_{i}$ of any agent $i \in N$ cannot exceed its marginal contribution; otherwise $x_{i}>f\left(\omega_{N}\right)-f\left(\omega_{N \backslash\{i\}}\right)$ and thus $f\left(\omega_{N}\right)-x_{i}=$ $x_{N}-x_{i}=x_{N \backslash\{i\}}<f\left(\omega_{N \backslash\{i\}}\right)$, but this would contradict $x$ to be a core element.
} 


$$
x_{i} \leq f\left(\omega_{N}\right)-f\left(\omega_{N \backslash\{i\}}\right)=\omega_{i} \cdot \frac{f\left(\omega_{N}\right)}{\omega_{N}},
$$

where the last equality follows from hypothesis (2) of the proposition. Hence, by efficiency of any core allocation, we reach $x=P(N, f, \omega)$.

In the proof of this result we have shown that vector $x^{i}$ defined in (3) is in the core of the problem, for any arbitrary agent $i \in N$. This shows that the marginal contribution of any agent $i \in N, f\left(\omega_{N}\right)-f\left(\omega_{N \backslash\{i\}}\right)$, is always attainable as a payoff to this agent in the core of any co-investment problem.

\section{Acceptable core allocations}

As we have commented in the introduction, we are interested in a subset of the core of the co-investment problem $(N, f, \omega)$. This subset includes all core allocations that meet the following incentive test: if some agents increase their initial investment, their expectations of receiving a higher payoff can be supported by the existence of a new core element that guarantees this larger payoff. Next proposition shows that any core allocation satisfies this requirement if just one agent increases the input contribution.

Proposition 2 Let $(N, f, \omega)$ and $\left(N, f, \omega^{\prime}\right)$ be two co-investment problems such that, for some $i^{*} \in N, \omega_{i^{*}}^{\prime}>\omega_{i^{*}}$ and $\omega_{j}^{\prime}=\omega_{j}$, for all $j \in N \backslash\left\{i^{*}\right\}$. Then, for any core allocation $x \in C(N, f, \omega)$ there exists $x^{\prime} \in C\left(N, f, \omega^{\prime}\right)$ such that $x_{i^{*}}^{\prime}>x_{i^{*}}$.

Proof Since $x \in C(N, f, \omega)$ it holds $x_{i^{*}} \leq f\left(\omega_{N}\right)-f\left(\omega_{N \backslash\left\{i^{*}\right\}}\right)$. Taking this fact into account, take $x^{\prime}$ as:

$$
\begin{aligned}
& x_{i^{*}}^{\prime}=f\left(\omega_{N}^{\prime}\right)-f\left(\omega_{N \backslash\left\{i^{*}\right\}}^{\prime}\right) \\
& x_{i}^{\prime}=\omega_{i}^{\prime} \cdot \frac{f\left(\omega_{N \backslash\left\{i^{*}\right\}}^{\prime}\right)}{\omega_{N \backslash\left\{i^{*}\right\}}^{\prime}} \text { for } i \neq i^{*} .
\end{aligned}
$$

Recall that we have already argued in the proof of Proposition 1 that $x^{i^{*}}$ is a core allocation, that is $x^{\prime}=x^{i^{*}} \in C\left(N, f, \omega^{\prime}\right)$. Being $x_{N}^{\prime}=f\left(\omega_{N}^{\prime}\right)$ and, since $\omega_{N}^{\prime}>\omega_{N}>0$ and thus $f\left(\omega_{N}^{\prime}\right)>f\left(\omega_{N}\right)$, it is straightforward that

$$
\begin{aligned}
x_{i^{*}}^{\prime} & =f\left(\omega_{N}^{\prime}\right)-f\left(\omega_{N \backslash\left\{i^{*}\right\}}^{\prime}\right) \\
& >f\left(\omega_{N}\right)-f\left(\omega_{N \backslash\left\{i^{*}\right\}}\right) \geq x_{i^{*}},
\end{aligned}
$$

where we have used the fact that $\omega_{N \backslash\left\{i^{*}\right\}}=\omega_{N \backslash\left\{i^{*}\right\}}^{\prime}$. And we end the proof.

Unfortunately, Proposition 2 cannot be generalized to the case where two or more agents increase their initial contribution. Next example shows that, if two agents increase their contribution at the same time, not every initial core allocation can be adapted to the new problem, that is, both players cannot benefit simultaneously from increasing their initial contribution. 
Example 1 Let $\omega=(1,2,3)$ be the vector of initial endowments for a three-agent coinvestment problem where $f(x)=x$, for $0 \leq x<5$, and $f(x)=1.5 \cdot x$, for $5 \leq x$. The allocation $x=(1,5,3)$ is in the core of the problem, $C(N, f, \omega)$. Let us suppose that players 1 and 2 increase their initial contribution by 1 unit, that is $\omega^{\prime}=(1+1,2+1,3)=(2,3,3)$. Notice that for any core element $x^{\prime} \in C\left(N, f, \omega^{\prime}\right)$ it holds $x_{2}^{\prime} \leq f\left(\omega_{N}^{\prime}\right)-f\left(\omega_{\{1,3\}}^{\prime}\right)=4.5$. Therefore, it is not possible to find a core element $x^{\prime} \in C\left(N, f, \omega^{\prime}\right)$ such that $x_{1}^{\prime}>x_{1}$ and $x_{2}^{\prime}>x_{2}=5$.

The above example shows that the core vector $x=(1,5,3)$ is not acceptable since agent 2 has received an excessive amount at the initial distribution: it is not possible to increase his payoff without breaking the stability of the allocation. The next definition formally states when an allocation is acceptable given $\omega^{\prime}$.

Definition 1 Given a co-investment problem $(N, f, \omega)$ and a vector $\omega^{\prime} \in \mathbb{R}^{N}$, with $\omega^{\prime} \geq \omega$, we say that a core allocation $x \in C(N, f, \omega)$ is acceptable with respect to $\omega^{\prime}$ if there is $x^{\prime} \in C\left(N, f, \omega^{\prime}\right)$ such that $x_{i}^{\prime}>x_{i}$ for all $i \in N$ with $\omega_{i}^{\prime}>\omega_{i}$. We denote the set of all acceptable core allocations with respect to $\omega^{\prime}, \omega^{\prime} \geq \omega$, by $A_{\omega^{\prime}}(N, f, \omega)$.

Notice that if $\omega^{\prime}=\omega$ the acceptable core coincides with the core. Furthermore, as we have already pointed out in the introduction, next proposition shows that the proportional allocation satisfies the interesting property of being always acceptable.

Proposition 3 For any co-investment problem $(N, f, \omega)$, the proportional distribution $P(N, f, \omega)$ is acceptable with respect to any $\omega^{\prime} \in \mathbb{R}^{N}, \omega^{\prime} \geq \omega$.

Proof Recall $P(N, f, \omega) \in C(N, f, \omega)$. Let us assume $\omega^{\prime} \geq \omega, \omega^{\prime} \neq \omega$, since the case $\omega^{\prime}=\omega$ is trivial. As $\omega^{\prime}(N)>\omega(N)>0$ we have $\frac{f\left(\omega_{N}^{\prime}\right)}{\omega_{N}^{\prime}} \geq \frac{f\left(\omega_{N}\right)}{\omega_{N}}>0$. Now take $x^{\prime}=$ $P\left(N, f, \omega^{\prime}\right) \in C\left(N, f, \omega^{\prime}\right)$. Hence,

$$
x_{i}^{\prime}=\frac{f\left(\omega_{N}^{\prime}\right)}{\omega_{N}^{\prime}} \cdot \omega_{i}^{\prime}>\frac{f\left(\omega_{N}\right)}{\omega_{N}} \cdot \omega_{i}=P_{i}(N, f, \omega),
$$

for all $i \in N$ such that $\omega_{i}^{\prime}>\omega_{i}$. And we are done.

Next theorem gives an algebraic description of the acceptable core set with respect to $\omega^{\prime}, \omega^{\prime} \geq \omega$. This characterization is useful and allows to develop interesting properties and numerical examples. For instance, we will use it in Example 2 to check that the acceptable core might be a proper subset of the core.

Theorem 1 Let $(N, f, \omega)$ be a co-investment problem and $\omega^{\prime} \in \mathbb{R}^{N}$ an input vector such that $\omega^{\prime} \geq \omega$. The acceptable core of $(N, f, \omega)$ with respect to $\omega^{\prime}, A_{\omega^{\prime}}(N, f, \omega)$, is described by the core elements $x \in C(N, f, \omega)$ satisfying the strict inequalities

$$
x_{R}<f\left(\omega_{N}^{\prime}\right)-f\left(\omega_{N \backslash R}^{\prime}\right),
$$

for all nonempty $R \subseteq S^{*}=\left\{i \in N \mid \omega_{i}^{\prime}>\omega_{i}\right\}, R \neq S^{*}$. 
Proof If $\omega^{\prime}=\omega$, then $S^{*}=\varnothing$ and the result holds trivially. From now on, let us suppose $\omega^{\prime} \neq \omega$ and thus $S^{*} \neq \varnothing$. First of all, for any acceptable core element $x \in A_{\omega^{\prime}}(N, f, \omega)$ there is $x^{\prime} \in C\left(N, f, \omega^{\prime}\right)$ such that $x_{i}^{\prime}>x_{i}$, for all $i \in S^{*}$. Hence, for all nonempty $R \subseteq S^{*}$, $R \neq S^{*}$, we have

$$
x_{R}<x_{R}^{\prime} \leq f\left(\omega_{N}^{\prime}\right)-f\left(\omega_{N \backslash R}^{\prime}\right),
$$

where the last inequality follows since $x^{\prime} \in C\left(N, f, \omega^{\prime}\right)$. Therefore, $x$ satisfies the inequalities given in the statement of the theorem.

To see the other inclusion, let $x \in C(N, f, \omega)$ be a core element. Notice that

$$
x_{S^{*}} \leq f\left(\omega_{N}\right)-f\left(\omega_{N \backslash S^{*}}\right)=f\left(\omega_{N}\right)-f\left(\omega_{N \backslash S^{*}}^{\prime}\right)<f\left(\omega_{N}^{\prime}\right)-f\left(\omega_{N \backslash S^{*}}^{\prime}\right) .
$$

Then, define vector $z \in \mathbb{R}^{N}$ as follows:

$$
\begin{aligned}
& z_{i}=x_{i}+\frac{\varepsilon}{\left|S^{*}\right|} \text { if } i \in S^{*} \\
& z_{i}=x_{i} \quad \text { if } i \in N \backslash S^{*},
\end{aligned}
$$

where $0<\varepsilon<\min \left\{\min _{\varnothing \neq R \subseteq S^{*}}\left\{f\left(\omega_{N}^{\prime}\right)-f\left(\omega_{N \backslash R}^{\prime}\right)-x_{R}\right\}, f\left(\omega_{N}^{\prime}\right)-f\left(\omega_{N}\right)\right\}$. Notice $\varepsilon$ is well defined by (5), (6) and the hypothesis of the theorem.

We claim vector $z$ satisfies: (i) for all nonempty $R \subseteq S^{*}, z_{R}<f\left(\omega_{N}^{\prime}\right)-f\left(\omega_{N \backslash R}^{\prime}\right)$ and (ii) $z_{N}<f\left(\omega_{N}^{\prime}\right)$. For proving (i) notice that for all $R \subseteq S^{*}, R \neq \varnothing$, we have

$$
z_{R}=x_{R}+\frac{\varepsilon|R|}{\left|S^{*}\right|} \leq x_{R}+\varepsilon<x_{R}+f\left(\omega_{N}^{\prime}\right)-f\left(\omega_{N \backslash R}^{\prime}\right)-x_{R}=f\left(\omega_{N}^{\prime}\right)-f\left(\omega_{N \backslash R}^{\prime}\right) .
$$

For proving (ii) notice that

$$
z_{N}=x_{N}+\varepsilon<x_{N}+f\left(\omega_{N}^{\prime}\right)-f\left(\omega_{N}\right)=f\left(\omega_{N}^{\prime}\right) .
$$

Next we define the set ${ }^{3}$

$$
\mathscr{D}_{S^{*}}=\left\{\begin{array}{c}
\varnothing \neq R=\left\{i_{1}, \ldots, i_{r}\right\} \subseteq S^{*}: \exists \theta=\left(i_{1}, \ldots, i_{r}\right) \in \Theta^{R} \text { such that } \\
z_{i_{1}} \geq \frac{f\left(\omega_{N}^{\prime}\right)}{\omega_{N}^{\prime}} \cdot \omega_{i_{1}}^{\prime}, \\
z_{i_{2}} \geq \max _{Q \subseteq\left\{i_{1}\right\}}\left\{\frac{\left.f\left(\omega_{\left(N \backslash\left\{i_{1}\right\}\right) \cup Q}^{\prime}\right)-z_{Q}\right\}}{\left.\omega_{N \backslash\left\{i_{1}\right\}}^{\prime}\right\} \cdot \omega_{i_{2}}^{\prime},}\right. \\
\vdots \\
z_{i_{r}} \geq \max _{Q \subseteq\left\{i_{1}, \ldots, i_{r-1}\right\}}\left\{\frac{f\left(\omega_{\left(N \backslash\left\{i_{1}, \ldots, i_{r-1}\right\}\right) \cup Q}^{\prime}\right)-z_{Q}}{\left.\omega_{N \backslash\left\{i_{1}, \ldots, i_{r-1}\right\}}^{\prime}\right\}}\right\} \cdot \omega_{i_{r}}^{\prime} .
\end{array}\right\}
$$

The next claim states that for any coalition $R$ in $\mathscr{D}_{S^{*}}$, there are increasing average adjusted returns outside $R$. The proof can be found in the Appendix.

\footnotetext{
${ }^{3}$ Given $R \subseteq N$, we denote by $\Theta^{R}$ the set of all permutations of the elements of $R$.
} 
Claim.- For any $R \in \mathscr{D}_{S^{*}}$ and for any pair of coalitions $S_{1}$ and $S_{2}$ such that $\varnothing \neq S_{1} \subseteq S_{2} \subseteq$ $N \backslash R$ and any $Q \subseteq R$ we have

$$
\frac{f\left(\omega_{S_{1} \cup Q}^{\prime}\right)-z_{Q}}{\omega_{S_{1}}^{\prime}} \leq \frac{f\left(\omega_{S_{2} \cup Q}^{\prime}\right)-z_{Q}}{\omega_{S_{2}}^{\prime}} .
$$

We use this claim to finish the proof of the theorem. We consider two cases:

Case 1.- $\mathscr{D}_{S^{*}}=\varnothing$. In this case, just by definition of $\mathscr{D}_{S^{*}}$, it follows that $\frac{f\left(\omega_{N}^{\prime}\right)}{\omega_{N}^{\prime}} \cdot \omega_{i}^{\prime}>z_{i}$, for all $i \in S^{*}$, since otherwise at least the coalition $\{i\}$ is in $\mathscr{D}_{S^{*}}$, for some $i \in S^{*}$. Now taking $x^{\prime}=P\left(N, f, \omega^{\prime}\right)$ we have $x^{\prime} \in C\left(N, f, \omega^{\prime}\right)$ and $x_{i}^{\prime}=\frac{f\left(\omega_{N}^{\prime}\right)}{\omega_{N}^{\prime}} \cdot \omega_{i}^{\prime}>z_{i} \geq x_{i}$, for all $i \in S^{*}$ which shows vector $x$ is in the acceptable core with respect to $\omega^{\prime}$.

Case 2.- $\mathscr{D}_{S^{*}} \neq \varnothing$. Let $R^{*}$ be a maximal coalition with respect to the inclusion in $\mathscr{D}_{S^{*}}$. Denote $R^{*}=\left\{i_{1}, \ldots, i_{r^{*}}\right\}$ where $\theta^{*}=\left(i_{1}, \ldots i_{r^{*}}\right)$ is the permutation of the set $R^{*}$ that fulfills all the inequalities of $\mathscr{D}_{S^{*}}$. We first check that $R^{*} \neq N$. To see it, if $R^{*}=N$, then $R^{*}=\left\{i_{1}, i_{2}, \ldots, i_{n}\right\}$ and, by definition of $\mathscr{D}_{S^{*}}$, we would have

$$
\begin{aligned}
z_{i_{n}} & \geq \max _{Q \subseteq N \backslash\left\{i_{n}\right\}}\left\{\frac{f\left(\omega_{\left(N \backslash\left\{i_{1}, \ldots, i_{n-1}\right\}\right) \cup Q}^{\prime}\right)-z_{Q}}{\left.\omega_{N \backslash\left\{i_{1}, \ldots, i_{n-1}\right\}}^{\prime}\right\} \cdot \omega_{i_{n}}^{\prime}}\right. \\
& =\max _{Q \subseteq N \backslash\left\{i_{n}\right\}}\left\{\frac{f\left(\omega_{\left\{i_{n}\right\} \cup Q}^{\prime}\right)-z_{Q}}{\omega_{\left\{i_{n}\right\}}^{\prime}}\right\} \cdot \omega_{i_{n}}^{\prime} \geq f\left(\omega_{N}^{\prime}\right)-z_{N \backslash\left\{i_{n}\right\}},
\end{aligned}
$$

which implies $z_{N} \geq f\left(\omega_{N}^{\prime}\right)$ and contradicts (8). Thus, we conclude $R^{*} \subseteq S^{*}$ and $R^{*} \neq \varnothing, N$.

Now define the vector $x^{\prime} \in \mathbb{R}^{N}$ as follows:

$$
\begin{aligned}
& x_{i}^{\prime}=z_{i}, \quad \text { for all } i \in R^{*} \\
& x_{i}^{\prime}=\frac{\max _{Q \subseteq R^{*}}\left\{f\left(\omega_{\left(N \backslash R^{*}\right) \cup Q}^{\prime}\right)-z_{Q}\right\}}{\omega_{N \backslash R^{*}}^{\prime}} \cdot \omega_{i}^{\prime}, \text { for all } i \in N \backslash R^{*} .
\end{aligned}
$$

To complete the proof we must show that $x_{i}^{\prime}>x_{i}$ for all $i \in S^{*}$ and that $x^{\prime} \in C\left(N, f, \omega^{\prime}\right)$. The strict inequalities follow since, by definition of vector $x^{\prime}$, we have

$$
\begin{aligned}
& x_{i}^{\prime}=z_{i}=x_{i}+\frac{\varepsilon}{\left|S^{*}\right|}>x_{i}, \text { for any } i \in R^{*} \text { and } \\
& x_{i}^{\prime}=\max _{Q \subseteq R^{*}}\left\{\frac{f\left(\omega_{\left(N \backslash R^{*}\right) \cup Q}^{\prime}\right)-z_{Q}}{\omega_{N \backslash R^{*}}^{\prime}}\right\} \cdot \omega_{i}^{\prime}>z_{i}=x_{i}+\frac{\varepsilon}{\left|S^{*}\right|}>x_{i}, \text { for any } i \in S^{*} \backslash R^{*},
\end{aligned}
$$

where the first strict inequality in the last expression comes from the maximality of coalition $R^{*}$ in the set $\left(\mathscr{D}_{S^{*}}, \subseteq\right)$.

For proving $x^{\prime} \in C\left(N, f, \omega^{\prime}\right)$, let us first check that vector $x^{\prime}$ is efficient for $\left(N, f, \omega^{\prime}\right)$, that is, $x^{\prime}(N)=f\left(\omega_{N}^{\prime}\right)$. Indeed, 


$$
x_{N}^{\prime}=z_{R^{*}}+\frac{\max _{Q \subseteq R^{*}}\left\{f\left(\omega_{\left(N \backslash R^{*}\right) \cup Q}^{\prime}\right)-z_{Q}\right\}}{\omega_{N \backslash R^{*}}^{\prime}} \cdot \omega_{N \backslash R^{*}}^{\prime}=z_{R^{*}}+f\left(\omega_{N}^{\prime}\right)-z_{R^{*}}=f\left(\omega_{N}^{\prime}\right),
$$

where the second equality holds since, for any $Q \subseteq R^{*}, Q \neq R^{*}$, we have

$$
\begin{gathered}
f\left(\omega_{N}^{\prime}\right)-f\left(\omega_{\left(N \backslash R^{*}\right) \cup Q}^{\prime}\right)=f\left(\omega_{N}^{\prime}\right)-f\left(\omega_{N \backslash\left(R^{*} \backslash Q\right)}^{\prime}\right) \\
>x_{R^{*} \backslash Q}+\varepsilon \geq x_{R^{*} \backslash Q}+\frac{\left|R^{*} \backslash Q\right|}{\left|S^{*}\right|} \cdot \varepsilon=z_{R^{*} \backslash Q} \\
=z_{R^{*}}-z_{Q},
\end{gathered}
$$

which implies that

$$
f\left(\omega_{N}^{\prime}\right)-z_{R^{*}}>f\left(\omega_{\left(N \backslash R^{*}\right) \cup Q}^{\prime}\right)-z_{Q}, \text { for any } Q \subseteq R^{*}, Q \neq R^{*} .
$$

To prove the core inequalities of the vector $x^{\prime}$, we must check that

$$
x_{T}^{\prime} \geq f\left(\omega_{T}^{\prime}\right) \text { for all } T \subseteq N, T \neq \varnothing, N .
$$

To this aim recall $R^{*}=\left\{i_{1}, \ldots, i_{r^{*}}\right\}$ and $\theta^{*}=\left(i_{1}, \ldots, i_{r^{*}}\right)$. Then, two subcases are considered:

Case 2.a.- Coalition $T$ satisfies $T \subseteq R^{*}=\left\{i_{1}, \ldots, i_{r^{*}}\right\}$. If $T=\left\{i_{1}\right\}$, then since $R^{*} \in \mathscr{D}_{S^{*}}$, we have

$$
x_{i_{1}}^{\prime}=z_{i_{1}} \geq \frac{f\left(\omega_{N}^{\prime}\right)}{\omega_{N}^{\prime}} \cdot \omega_{i_{1}}^{\prime} \geq \frac{f\left(\omega_{i_{1}}^{\prime}\right)}{\omega_{i_{1}}^{\prime}} \cdot \omega_{i_{1}}^{\prime}=f\left(\omega_{i_{1}}^{\prime}\right)
$$

If $T \subseteq R^{*}, T \neq\left\{i_{1}\right\}$, let $i_{t}$ be the latest agent in $T$ with respect to the permutation $\theta^{*}=\left(i_{1}, i_{2}, \ldots, i_{r^{*}}\right)$ of coalition $R^{*}=\left\{i_{1}, i_{2}, \ldots, i_{r^{*}}\right\}$. In other words $i_{t}$ is the unique agent of $T$ satisfying $T \backslash\left\{i_{t}\right\} \subseteq\left\{i_{1}, \ldots, i_{t-1}\right\}$. Then, we have

$$
\begin{aligned}
x_{i_{t}}^{\prime} & =z_{i_{t}} \geq \frac{\max _{Q \subseteq\left\{i_{1}, \ldots, i_{t-1}\right\}}\left\{f\left(\omega_{\left(N \backslash\left\{i_{1}, \ldots, i_{t-1}\right\}\right) \cup Q}^{\prime}\right)-z_{Q}\right\}}{\omega_{N \backslash\left\{i_{1}, \ldots, i_{t-1}\right\}}^{\prime}} \cdot \omega_{i_{t}}^{\prime} \\
& \geq \frac{\max _{Q \subseteq\left\{i_{1}, \ldots, i_{t-1}\right\}}\left\{f\left(\omega_{\left\{i_{t}\right\} \cup Q}^{\prime}\right)-z_{Q}\right\}}{\omega_{\left\{i_{t}\right\}}^{\prime}} \cdot \omega_{i_{t}}^{\prime} \\
& \geq f\left(\omega_{\left\{i_{t}\right\} \cup\left(T \backslash\left\{i_{t}\right\}\right)}^{\prime}\right)-z_{T \backslash\left\{i_{t}\right\}}=f\left(\omega_{T}^{\prime}\right)-z_{T \backslash\left\{i_{t}\right\}},
\end{aligned}
$$

and thus we obtain the inequality $x_{T}^{\prime} \geq f\left(\omega_{T}^{\prime}\right)$. In the above argument, the first inequality comes from the definition of $\mathscr{D}_{S^{*}}$, and the second one follows by (9) applied to $R=$ $\left\{i_{1}, i_{2}, \ldots, i_{t-1}\right\} \in \mathscr{D}_{S^{*}}, S_{1}=\left\{i_{t}\right\}$ and $S_{2}=N \backslash\left\{i_{1}, \ldots, i_{t-1}\right\}$. Finally, the last inequality comes from taking $Q=T \backslash\left\{i_{t}\right\}$. 
Case 2.b.- Coalition $T$ satisfies $T \cap\left(N \backslash R^{*}\right) \neq \varnothing$. In this case, we have

$$
\begin{aligned}
& x_{T}^{\prime}=x_{T \cap\left(N \backslash R^{*}\right)}^{\prime}+x_{T \cap R^{*}}^{\prime} \\
&=\frac{\max _{Q \subseteq R^{*}}\left\{f\left(\omega_{\left(N \backslash R^{*}\right) \cup Q}^{\prime}\right)-z_{Q}\right\}}{\omega_{N \backslash R^{*}}^{\prime}} \cdot \omega_{T \cap\left(N \backslash R^{*}\right)}^{\prime}+z_{T \cap R^{*}} \\
& \geq \frac{\max _{Q \subseteq R^{*}}\left\{f\left(\omega_{\left(T \cap\left(N \backslash R^{*}\right)\right) \cup Q}^{\prime}\right)-z_{Q}\right\}}{\omega_{T \cap\left(N \backslash R^{*}\right)}^{\prime}} \cdot \omega_{T \cap\left(N \backslash R^{*}\right)}^{\prime}+z_{T \cap R^{*}} \\
& \geq f\left(\omega_{\left(T \cap\left(N \backslash R^{*}\right)\right) \cup\left(T \cap R^{*}\right)}^{\prime}\right)-z_{T \cap R^{*}}+z_{T \cap R^{*}}=f\left(\omega_{T}^{\prime}\right),
\end{aligned}
$$

where the first inequality comes from (9) taking $R=R^{*}, S_{1}=T \cap\left(N \backslash R^{*}\right) \neq \varnothing$ and $S_{2}=N \backslash R^{*}$ and the second inequality taking $Q=T \cap R^{*}$. And the proof of the theorem concludes

Let us remark that Proposition 2 is in fact a special case of Theorem 1, when $\left|S^{*}\right|=1$; for this case no strict inequality needs to be checked and hence, the result of the theorem is unconditional. Nevertheless, the proof of Proposition 2 contributes with a direct and explicit core allocation that improves the payoff to the single agent that increases his contribution.

The above characterization offers a new inside to understand the trade off between core stability and incentive monotonicity. It states a positive and useful tool to check whether an allocation is acceptable in the context of co-investment problems. For instance, coming back to Example 1, it is easy to check that the acceptable core is described by the set

$$
A_{\omega^{\prime}}(N, f, \omega)=\left\{x \in C(N, f, \omega) \mid x_{1}<3 \text { and } x_{2}<4.5\right\} .
$$

In Figure 1 we represent this set, illustrating how the core is reduced. The core is the convex region determine by the points $A, B, C$ and $D(\square)$. The acceptable core with respect to $\omega^{\prime}=(2,3,3)$ is the convex subset determined by the subset $A, B, C$ and $E$ (‥:). Notice that the segment $\overline{C E}$ is not included in the acceptable core since the strict inequality $x_{2}<4.5$ applies; on the other way around, this example also shows how some of the constraints that determine the acceptable core do not apply (in the example, the inequality $x_{1}<3$ ).

\section{The acceptable core}

In the previous section we have characterized when a specific core allocation is acceptable with respect to some given input vector $\omega^{\prime}, \omega^{\prime} \geq \omega$. Now, we want to analyze the core allocations that are acceptable no matter the increase in the input contribution.

Definition 2 The acceptable core of a co-investment problem $(N, f, \omega)$ is the set

$$
A(N, f, \omega)=\bigcap_{\omega^{\prime} \geq \omega} A_{\omega^{\prime}}(N, f, \omega) .
$$




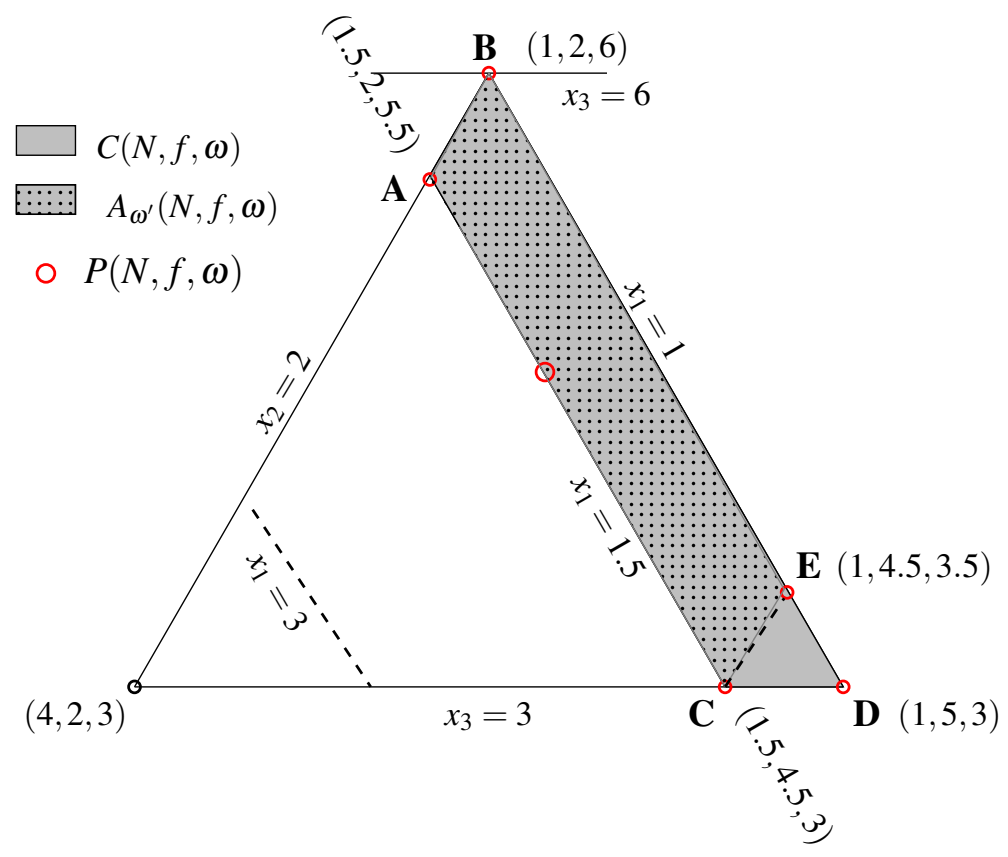

Fig. 1 The acceptable core $A_{\omega^{\prime}}(N, f, \omega)$ of Example 1 represented in the efficiency plane $x_{1}+$ $x_{2}+x_{3}=9$.

This is, a core allocation is acceptable if it is acceptable with respect to any $\omega^{\prime}, \omega^{\prime} \geq \omega$. Let us point out that the acceptable core of a co-investment problem is, by definition, a subset of its core. Moreover, we have already stated in Proposition 3 that the proportional allocation is always acceptable; thus, the acceptable core is nonempty since it contains at least this allocation. Summarizing these preliminaries

$$
P(N, f, \omega) \in A(N, f, \omega) \subseteq C(N, f, \omega) .
$$

The following example shows that the acceptable core might include several allocations, not only the proportional allocation, but it might be strictly smaller than the core.

Example 2 Let $N=\{1,2,3\}$ and $\omega=(100,200,300)$ be the vector of initial endowments of the agents. The co-investment function is:

$$
f(x)= \begin{cases}1 \% \cdot x & 0 \leq x \leq 300 \\ 2 \% \cdot x & 300<x \leq 400 \\ 3 \% \cdot x & 400<x \leq 600 \\ 4 \% \cdot x & 600<x\end{cases}
$$

The output of coalitions are:

$$
\begin{aligned}
& f\left(\omega_{1}\right)=1, f\left(\omega_{1}+\omega_{2}\right)=3, \\
& f\left(\omega_{2}\right)=2, f\left(\omega_{1}+\omega_{3}\right)=8, \quad f\left(\omega_{1}+\omega_{2}+\omega_{3}\right)=18 . \\
& f\left(\omega_{3}\right)=3, f\left(\omega_{2}+\omega_{3}\right)=15,
\end{aligned}
$$


The core of this game can be described as

$$
C(N, f, \omega)=\left\{\begin{array}{l|l}
\left(x_{1}, x_{2}, x_{3}\right) \in \mathbb{R}^{3} & \begin{array}{l}
x_{1}+x_{2}+x_{3}=18,1 \leq x_{1} \leq 3 \\
2 \leq x_{2} \leq 10 \text { and } 3 \leq x_{3} \leq 15
\end{array}
\end{array}\right\}
$$

and the proportional allocation is $P(N, f, \omega)=(3,6,9)$. It is interesting to point out that the proportional allocation assigns to the first agent the maximum payoff within the core of the game; graphically, see Figure 2, the proportional allocation (O) is located on the left border of the core $(\square)$ where agent 1 receives the largest possible reward within the core.

Now we claim that the acceptable core is given by

$$
A(N, f, \omega)=\left\{x \in C(N, f, \omega) \mid x_{1} \leq 4, x_{2} \leq 8 \text { and } x_{3} \leq 12\right\} .
$$

To see this, let $\left(x_{1}, x_{2}, x_{3}\right) \in C(N, f, \omega)$ be a core allocation such that $x_{1} \leq 4, x_{2} \leq 8$ and $x_{3} \leq 12$ and take $\omega^{\prime} \in \mathbb{R}_{++}^{N}, \omega^{\prime} \geq \omega=(100,200,300)$ and $\omega^{\prime} \neq \omega$. We can describe $\omega^{\prime}=\left(100+\varepsilon_{1}, 200+\varepsilon_{2}, 300+\varepsilon_{3}\right)$ where $\varepsilon_{1}, \varepsilon_{2}, \varepsilon_{3} \geq 0$ and $\varepsilon_{1}+\varepsilon_{2}+\varepsilon_{3}>0$.

Since $\omega_{1}^{\prime}+\omega_{2}^{\prime}+\omega_{3}^{\prime}=600+\varepsilon$, where $\varepsilon=\varepsilon_{1}+\varepsilon_{2}+\varepsilon_{3}>0$, we have

$$
f\left(\omega_{N}^{\prime}\right)=0.04 \cdot \omega_{N}^{\prime}=24+0.04 \varepsilon \text {. }
$$

Now take the proportional allocation with respect to $\omega^{\prime}$, that is, $P\left(N, f, \omega^{\prime}\right)=(4+$ $\left.0.04 \varepsilon_{1}, 8+0.04 \varepsilon_{2}, 12+0.04 \varepsilon_{3}\right)$. As the allocation $x=\left(x_{1}, x_{2}, x_{3}\right)$ satisfies $x_{1} \leq 4, x_{2} \leq 8$ and $x_{3} \leq 12$ it follows

$$
x_{1} \leq P_{1}\left(N, f, \omega^{\prime}\right), \quad x_{2} \leq P_{2}\left(N, f, \omega^{\prime}\right), \quad x_{3} \leq P_{3}\left(N, f, \omega^{\prime}\right) .
$$

Moreover, for any $i=1,2,3$, if $\varepsilon_{i}>0$ we also have $x_{i}<P_{i}\left(N, f, \omega^{\prime}\right)$ and $P\left(N, f, \omega^{\prime}\right) \in$ $C\left(N, f, \omega^{\prime}\right)$ which implies $\left(x_{1}, x_{2}, x_{3}\right) \in A(N, f, \omega)$.

To justify the other inclusion, let $x=\left(x_{1}, x_{2}, x_{3}\right) \in A(N, f, \omega)$. Taking $\omega^{\prime}(\varepsilon)=(100+$ $\varepsilon, 600,600)$, with $\varepsilon>0$ and by Theorem 1 , we know $x_{1}<f\left(\omega_{N}^{\prime}\right)-f\left(\omega_{N \backslash\{1\}}^{\prime}\right)=52+$ $0.04 \varepsilon-48=4+4 \varepsilon$, for all $\varepsilon>0$, or equivalently $x_{1} \leq 4$. The other inequalities can be reached by using $\omega^{\prime \prime}(\varepsilon)=(500,200+\varepsilon, 500)$ and $\omega^{\prime \prime \prime}(\varepsilon)=(400,400,300+\varepsilon), \varepsilon>0$, respectively.

In Figure 2 you can check that the acceptable core is larger than the proportional allocation, but strictly smaller than the core. Indeed, the acceptable core of this numerical example is the convex hull of the extreme points $\mathbf{A}=(3,3,12), \mathbf{B}=(1,5,12), \mathbf{C}=(1,8,9)$ and $\mathbf{D}=(3,8,7)$.

Since the acceptable core is included in the core, let us describe a sufficient condition for the coincidence of both sets. As the next proposition states, the condition is based on assuming the function $f$ to be convex ${ }^{4}$. It is interesting to remark that, when the function $f$ is convex, the output of the different coalitions $\left(f\left(\omega_{S}\right)\right)_{S \subseteq N}$ can be interpreted as a convex cooperative game (Shapley, 1971), although the converse is not true as Example 1 illustrates.

\footnotetext{
4 Moulin (1990) introduces in the analysis the convexity of the production function.
} 


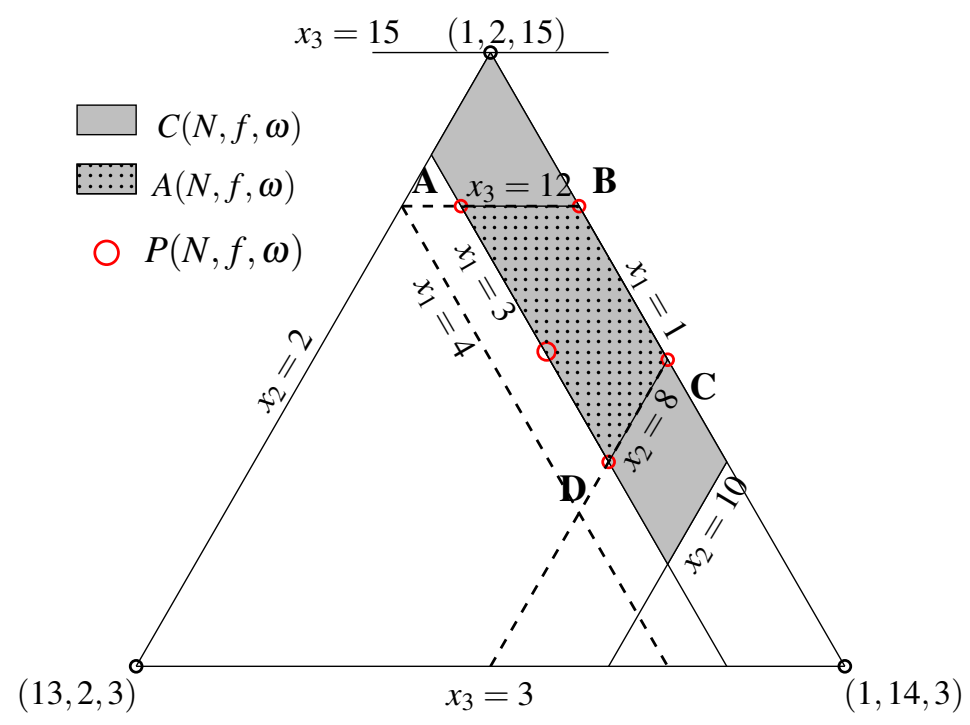

Fig. 2 The acceptable core of Example 2 in the efficiency plane $x_{1}+x_{2}+x_{3}=18$.

Proposition 4 Let $(N, f, \omega)$ be a co-investment problem and let $f$ be a convex function. Then,

$$
A(N, f, \omega)=C(N, f, \omega) .
$$

Proof Since $f$ is a convex function it holds that ${ }^{5}$, for all $0<x<y$ and $z>0$,

$$
f(y)-f(x) \leq f(y+z)-f(x+z) .
$$

Now, let $(N, f, \omega)$ be a co-investment problem and take a coalition $S^{*} \subseteq N, S^{*} \neq \varnothing$. Let us consider $\omega^{\prime} \in \mathbb{R}^{N}$ such that $\omega_{i}^{\prime}>\omega_{i}$ for all $i \in S^{*}$ and $\omega_{i}^{\prime}=\omega_{i}$, for all $i \in N \backslash S^{*}$.

We must first prove that inequalities (5) in Theorem 1 hold, for any $x \in C(N, f, \omega)$. To this aim consider an arbitrary coalition $\varnothing \neq R \subseteq S^{*}, R \neq S^{*}$ and let us suppose to the contrary $x_{R} \geq f\left(\omega_{N}^{\prime}\right)-f\left(\omega_{N \backslash R}^{\prime}\right)$. Then,

$$
\begin{aligned}
x_{R} & \geq f\left(\omega_{N}^{\prime}\right)-f\left(\omega_{N \backslash R}^{\prime}\right) \\
& \geq f\left(\omega_{N}^{\prime}-\left(\omega_{S^{*} \backslash R}^{\prime}-\omega_{S^{*} \backslash R}\right)\right)-f\left(\omega_{N \backslash R}^{\prime}-\left(\omega_{S^{*} \backslash R}^{\prime}-\omega_{S^{*} \backslash R}\right)\right) \\
& =f\left(\omega_{N}^{\prime}-\left(\omega_{S^{*} \backslash R}^{\prime}-\omega_{S^{*} \backslash R}\right)\right)-f\left(\omega_{N \backslash R}\right) \\
& >f\left(\omega_{N}\right)-f\left(\omega_{N \backslash R}\right) \geq x_{N}-x_{N \backslash R}=x_{R},
\end{aligned}
$$

where the second inequality comes from (11) taking $y=\omega_{N}^{\prime}-\left[\omega_{S^{*} \backslash R}^{\prime}-\omega_{S^{*} \backslash R}\right]>x=$ $\omega_{N \backslash R}^{\prime}-\left[\omega_{S^{*} \backslash R}^{\prime}-\omega_{S^{*} \backslash R}\right]>0$ and $z=\omega_{S^{*} \backslash R}^{\prime}-\omega_{S^{*} \backslash R}>0$. Moreover, the strict inequality holds since $\omega_{N}^{\prime}-\left(\omega_{S^{*} \backslash R}^{\prime}-\omega_{S^{*} \backslash R}\right)>\omega_{N}$ and $f\left(\omega_{N}\right)>0$, and the last inequality, since

\footnotetext{
5 see Klement et al. (2011), for example.
} 
$x \in C(N, f, \omega)$. Hence, we reach a contradiction. We conclude $x_{R}<f\left(\omega_{N}^{\prime}\right)-f\left(\omega_{N \backslash R}^{\prime}\right)$, for all non-empty coalitions $R \subseteq S^{*}, R \neq S^{*}$.

The previous result shows a particular situation where the acceptable core is as large as possible and coincides with the core. On the other side, next proposition states a sufficient condition for the acceptable core to just contain the proportional distribution. The condition requires that the average return remains constant beyond $\omega_{N}$.

Proposition 5 Let $(N, f, \omega)$ be a co-investment problem where the function $f$ is average stationary at $\omega_{N}$, i.e. $\frac{f(x)}{x}=\frac{f\left(\omega_{N}\right)}{\omega_{N}}$, for all $x \geq \omega_{N}$. Then,

$$
A(N, f, \omega)=\{P(N, f, \omega)\} .
$$

Proof Let $x \in A(N, f, \omega)$. For any agent $i \in N$ we take $\omega^{i}=\left(\omega_{k}^{i}\right)_{k \in N} \in \mathbb{R}^{N}$ as $\omega_{i}^{i}=\omega_{i}+\varepsilon$, where $\varepsilon>0$, and $\omega_{k}^{i}=\omega_{k}+\omega_{N}$, for all $k \in N, k \neq i$. By Theorem 1 we obtain

$$
\begin{aligned}
x_{i} & <f\left(\omega_{N}^{i}\right)-f\left(\omega_{N \backslash\{i\}}^{i}\right)=\left(n \cdot \omega_{N}+\varepsilon\right) \cdot \frac{f\left(\omega_{N}\right)}{\omega_{N}}-\left((n-1) \cdot \omega_{N}+\sum_{k \neq i} \omega_{K}\right) \cdot \frac{f\left(\omega_{N}\right)}{\omega_{N}} \\
& =\left(\omega_{i}+\varepsilon\right) \cdot \frac{f\left(\omega_{N}\right)}{\omega_{N}},
\end{aligned}
$$

where we have used that $f$ is average stationary at $\omega_{N}$. Being $\varepsilon>0$ arbitrary, we obtain $x_{i} \leq \omega_{i} \cdot \frac{f\left(\omega_{N}\right)}{\omega_{N}}$, for all $i \in N$, or equivalently, $x=P(N, f, \omega)$.

The above proposition shows that the acceptable core of Example 1 reduces to the proportional distribution $P(N, f, \omega)=(1.5,3,4.5)$; see Figure 1 for a graphical location.

\section{The proportional allocation: a characterization result.}

The proportional allocation is always acceptable (see Proposition 3). However, the acceptable core might include many other allocations. In this section we look at set-solutions that assigns to any co-investment problem a subset of the acceptable core and we characterize when this subset just contains the proportional allocation.

Let us denote by $\alpha$ a set-solution that assigns to any co-investment problem $(N, f, \omega)$ a nonempty subset of allocations of the problem $(N, f, \omega)$; this is

$$
\alpha(N, f, \omega) \subseteq\left\{x \in \mathbb{R}^{N} \mid x_{N}=f\left(\omega_{N}\right)\right\} .
$$

We propose the following three properties ${ }^{6}$ for $\alpha$.

Core selection. For any co-investment problem $(N, f, \omega), \alpha(N, f, \omega) \subseteq C(N, f, \omega)$.

Core invariance. For any pair of co-investment problems $(N, f, \omega)$ and $\left(N, f^{\prime}, \omega\right)$ we require

$$
\left\{C(N, f, \omega)=C\left(N, f^{\prime}, \omega\right)\right\} \Rightarrow\left\{\alpha(N, f, \omega)=\alpha\left(N, f^{\prime}, \omega\right)\right\} .
$$

Incentive monotonicity. Let $\omega^{\prime}, \omega \in \mathbb{R}^{N}$ such that $\omega^{\prime} \geq \omega$. Then, for any $x \in \alpha(N, f, \omega)$, there exists $x^{\prime} \in \alpha\left(N, f, \omega^{\prime}\right)$ such that $x_{i}^{\prime}>x_{i}$, for all $i \in N$ with $\omega_{i}^{\prime}>\omega_{i}$.

\footnotetext{
6 These properties are adapted from Di Luca et al. (2013).
} 
Theorem 2 For any co-investment problem, $(N, f, \omega)$ a set-solution $\alpha$ contains just the proportional distribution, $\alpha(N, f, \omega)=\{P(N, f, \omega)\}$, if and only if $\alpha$ satisfies core selection, core invariance and incentive monotonicity.

Proof Suppose $\alpha$ is a set-solution such that, for any co-investment problem $\alpha(N, f, \omega)=$ $\{P(N, f, \omega)\}$. Since $P(N, f, \omega)$ is always a core element, then $\alpha$ satisfies core selection. Moreover, if $C(N, f, \omega)=C\left(N, f^{\prime}, \omega\right)$, then $f\left(\omega_{N}\right)=f^{\prime}\left(\omega_{N}\right)$ and thus $\alpha(N, f, \omega)=$ $\alpha\left(N, f^{\prime}, \omega\right)$. Finally, it satisfies incentive monotonicity, since $P_{i}(N, f, \omega)<P_{i}\left(N, f, \omega^{\prime}\right)$, for all $i \in N$ with $\omega_{i}^{\prime}>\omega_{i}$.

Now, on the other hand, let us suppose a set-solution $\alpha$ satisfying all the three properties and take $x \in \alpha(N, f, \omega)$. Now, define the function $f^{\prime}$ as follows: $f^{\prime}(x)=f(x)$, if $x \leq \omega_{N}$, and $f^{\prime}(x)=\frac{f\left(\omega_{N}\right)}{\omega_{N}} \cdot x$, if $x>\omega_{N}$. By definition of the function $f^{\prime}$, we have $C(N, f, \omega)=C\left(N, f^{\prime}, \omega\right)$ and thus, by core invariance, $x \in \alpha\left(N, f^{\prime}, \omega\right)=\alpha(N, f, \omega)$.

Next, select an arbitrary pair of different agents $i$ and $j$ and, given $\varepsilon>0$, define $\omega^{\prime}(\varepsilon)=\left(\omega_{1}^{\prime}(\varepsilon), \omega_{2}^{\prime}(\varepsilon), \ldots, \omega_{n}^{\prime}(\varepsilon)\right) \in \mathbb{R}^{N}$ as $\omega_{i}^{\prime}(\varepsilon)=\omega_{i}+\varepsilon, \omega_{j}^{\prime}(\varepsilon)=\omega_{j}+\omega_{N}$ and $\omega_{k}^{\prime}(\varepsilon)=$ $\omega_{k}$, otherwise. Since $\alpha$ satisfies incentive monotonicity and $\omega_{i}^{\prime}(\varepsilon)>\omega_{i}$, there exists $x^{\prime} \in$ $\alpha\left(N, f^{\prime}, \omega^{\prime}(\varepsilon)\right)$ such that $x_{i}^{\prime}>x_{i}$. Furthermore, since $\alpha$ satisfies core selection we have that $x^{\prime} \in C\left(N, f^{\prime}, \omega^{\prime}(\varepsilon)\right)$ and thus $x_{i}^{\prime}$ is bounded above by the marginal contribution of agent $i$, this is

$$
x_{i}<x_{i}^{\prime} \leq f^{\prime}\left(\omega_{N}^{\prime}(\varepsilon)\right)-f^{\prime}\left(\omega_{N \backslash\{i\}}^{\prime}(\varepsilon)\right)=\frac{f\left(\omega_{N}\right)}{\omega_{N}} \cdot\left(\omega_{i}+\varepsilon\right) .
$$

Since $x_{i}<\frac{f\left(\omega_{N}\right)}{\omega_{N}} \cdot\left(\omega_{i}+\varepsilon\right)$ should hold for any $\varepsilon>0$ we get that $x_{i} \leq \frac{f\left(\omega_{N}\right)}{\omega_{N}} \cdot \omega_{i}$. As agents $i$ and $j$ have been arbitrarily selected, we conclude that

$$
x_{i} \leq \frac{f\left(\omega_{N}\right)}{\omega_{N}} \cdot \omega_{i}, \text { for all } i \in N
$$

Finally, since $x$ is an allocation for the problem $(N, f, \omega)$ we conclude $x_{i}=\frac{f\left(\omega_{N}\right)}{\omega_{N}} \cdot \omega_{i}$, for all $i \in N$ and thus $x=P(N, f, \omega)$.

Let us point out that the three properties are logically independent. The core, i.e. $\alpha(N, f, \omega)=C(N, f, \omega)$ satisfies core selection, core invariance, but, as we have analyzed, it is not incentive monotonic. The set solution that contains only the equal division allocation, $\alpha(N, f, \omega)=\left\{\left(x_{i}=\frac{f\left(\omega_{N}\right)}{|N|}\right)_{i \in N}\right\}$, satisfies core invariance, incentive montonicity, but it is not a core selection. Finally, the solution defined as $\alpha(N, f, \omega)=C(N, f, \omega)$, if $f$ is a convex function, and $\alpha(N, f, \omega)=\{P(N, f, \omega)\}$, if $f$ is not convex, satisfies core selection, incentive monotonicity, but it is not core invariant.

\section{Conclusions}

In this paper, we have described and analyzed co-investment problems and the compatibility between a stability principle and an incentive principle. The two principles collaborate 
to reinforce cooperation: the first one avoids breaking cooperation; the second one guarantees the effort of each agent is rewarded accordingly. The analysis carried out in the paper focus on testing core allocations. A core allocation is validated if, in the eventual situation where some arbitrary agents increase their contribution, there is another core allocation that give those agents a larger payoff. There is another interesting aspect that is not analyzed in this paper and refers to the study of the compatibility of the two principles applied to allocation rules. That is, given a rule that assigns to each co-investment problem a unique stable allocation, does this rule assign a larger payoff to some agents whenever they increase their contribution? Does it exist at least one such a rule? The answer to this last question is in the positive: the proportional rule with respect to the resources contributed satisfies these requirements and it is one of the most used rules. However, the proportional rule assigns the same payoff per unit contributed and do not discriminate between agents with different contributions. It might be interesting to describe and characterize other possible allocation rules. Another aspect not covered by the analysis is the impact of the increase in the resource contribution made by some group of agents on the rest agents. In some cases, if we want to preserve stability, the increase in the payoff to some agents implies, with no option, the decrease in the payoff to other agents. This work is left for further research.

Last but not least, it seems interesting to introduce our analysis in the field of group buying problems or cooperative purchasing situations, see Anand and Aron (2003) or Schaarsberg et al. (2013). Focusing on bundling order quantities to obtain discounts, group buying problems are the counterpart of co-investment problems to analyze purchasing problems with decreasing average costs. Finally, the notion of average monotonicity which is the basis for co-investment problems has been analyzed and generalized in different areas of game theory as in Corcho and Ferreira (2003), Sagara and Vlach (2011), Liu et al.(2013), Liu and Tian (2014) or Hong (2016).

In Corcho and Ferreira (2003), generalized externality games are introduced. Two interesting economic situations fall inside this model: provision of public goods and joint venture among firms. Despite not to be co-investment problems, generalized externality games are average monotonic games and thus a parallel analysis similar to the one carried out in this paper gets its own interest. Sagara and Vlach (2011) extend the notion of average of monotonicity to cooperative games with a continuum of agents, reaching the non-emptiness of its core and leave open the coincidence between the core and some bargaining sets. In Liu et al. (2013) is proved that all the results for average monotonic cooperative games are suitable to be replicate in the field of cooperative fuzzy games including examples and models of financial applications. In Liu and Tian (2014) they exhibit, for the first time, the model of NTU fuzzy game associated to a financial cooperative problem. Finally, in Hong (2016) he introduces and develop the Average monotonic fuzzy interval cooperative games. In many of these works a parallel analysis like the one made in this paper could be applied. 


\section{Appendix}

Given a co-investment problem $(N, f, \omega), \omega^{\prime} \in \mathbb{R}^{N}, \omega^{\prime} \geq \omega, \omega^{\prime} \neq \omega$ and vector $z$ defined in (7) we have

Claim.- For any $R \in \mathscr{D}_{S^{*}}$ and for any pair of coalitions $S_{1}$ and $S_{2}$ such that $\varnothing \neq S_{1} \subseteq S_{2} \subseteq$ $N \backslash R$ we have

$$
\frac{f\left(\omega_{S_{1} \cup Q}^{\prime}\right)-z_{Q}}{\omega_{S_{1}}^{\prime}} \leq \frac{f\left(\omega_{S_{2} \cup Q}^{\prime}\right)-z_{Q}}{\omega_{S_{2}}^{\prime}} \text {, for any } Q \subseteq R .
$$

Proof The proof will be argued by induction on the cardinality of the size of coalition $R$. If $|R|=1$, i.e. $R=\left\{j_{1}\right\} \in \mathscr{D}_{S^{*}}$ there are just two cases. If $Q=\varnothing$ then (14) is

$$
\frac{f\left(\omega_{S_{1}}^{\prime}\right)}{\omega_{S_{1}}^{\prime}} \leq \frac{f\left(\omega_{S_{2}}^{\prime}\right)}{\omega_{S_{2}}^{\prime}}
$$

and it follows just by (1). If $Q=\left\{j_{1}\right\}$ then (14) is

$$
\frac{f\left(\omega_{S_{1} \cup\left\{j_{1}\right\}}^{\prime}\right)-z_{j_{1}}}{\omega_{S_{1}}^{\prime}} \leq \frac{f\left(\omega_{S_{2} \cup\left\{j_{1}\right\}}^{\prime}\right)-z_{j_{1}}}{\omega_{S_{2}}^{\prime}} .
$$

To check this last inequality, notice that

$$
\begin{aligned}
& \frac{f\left(\omega_{S_{1} \cup\left\{j_{1}\right\}}^{\prime}\right)-z_{j_{1}}}{\omega_{S_{1}}^{\prime}}=\frac{\frac{f\left(\omega_{S_{1} \cup\left\{j_{1}\right\}}^{\prime}\right)}{\omega_{S_{1} \cup\left\{j_{1}\right\}}^{\prime}} \cdot \omega_{S_{1}}^{\prime}+\frac{f\left(\omega_{S_{1} \cup\left\{j_{1}\right\}}^{\prime}\right)}{\omega_{S_{1} \cup\left\{j_{1}\right\}}^{\prime}} \cdot \omega_{j_{1}}^{\prime}-z_{j_{1}}}{\omega_{S_{1}}^{\prime}} \\
& =\frac{f\left(\omega_{S_{1} \cup\left\{j_{1}\right\}}^{\prime}\right)}{\omega_{S_{1} \cup\left\{j_{1}\right\}}^{\prime}}+\frac{\frac{f\left(\omega_{S_{1} \cup\left\{j_{1}\right\}}^{\prime}\right)}{\omega_{S_{1} \cup\left\{j_{1}\right\}}^{\prime}} \cdot \omega_{j_{1}}^{\prime}-z_{j_{1}}}{\omega_{S_{1}}^{\prime}} \leq \frac{f\left(\omega_{S_{2} \cup\left\{j_{1}\right\}}^{\prime}\right)}{\omega_{S_{2} \cup\left\{j_{1}\right\}}^{\prime}}+\frac{\frac{f\left(\omega_{S_{2} \cup\left\{j_{1}\right\}}^{\prime}\right)}{\omega_{S_{2} \cup\left\{j_{1}\right\}}^{\prime}} \cdot \omega_{j_{1}}^{\prime}-z_{j_{1}}}{\omega_{S_{1}}^{\prime}} \\
& \leq \frac{f\left(\omega_{S_{2} \cup\left\{j_{1}\right\}}^{\prime}\right)}{\omega_{S_{2} \cup\left\{j_{1}\right\}}^{\prime}}+\frac{\frac{f\left(\omega_{S_{2} \cup\left\{j_{1}\right\}}^{\prime}\right)}{\omega_{S_{2} \cup\left\{j_{1}\right\}}^{\prime}} \cdot \omega_{j_{1}}^{\prime}-z_{j_{1}}}{\omega_{S_{2}}^{\prime}}=\frac{f\left(\omega_{S_{2} \cup\left\{j_{1}\right\}}^{\prime}\right)-z_{j_{1}}}{\omega_{S_{2}}^{\prime}},
\end{aligned}
$$

where the first inequality follows by (1) and the second one since, by definition of the set $\mathscr{D}_{S^{*}}$, we have $z_{j_{1}} \geq \frac{f\left(\omega_{N}^{\prime}\right)}{\omega_{N}^{\prime}} \cdot \omega_{j_{1}}^{\prime} \geq \frac{f\left(\omega_{S_{2} \cup\left\{j_{1}\right\}}^{\prime}\right)}{\omega_{S_{2} \cup\left\{j_{1}\right\}}^{\prime}} \cdot \omega_{j_{1}}^{\prime}$, and thus $\frac{f\left(\omega_{S_{2} \cup\left\{j_{1}\right\}}^{\prime}\right)}{\omega_{S_{2} \cup\left\{j_{1}\right\}}^{\prime}} \cdot \omega_{j_{1}}^{\prime}-z_{j_{1}} \leq 0$.

Suppose now that for any $\widetilde{R} \in \mathscr{D}_{S^{*}}$ such that $1 \leq|\widetilde{R}| \leq k$ and all $Q \subseteq \widetilde{R}$ we have

$$
\frac{f\left(\omega_{\widetilde{S}_{1} \cup Q}^{\prime}\right)-z_{Q}}{\omega_{\widetilde{S}_{1}}^{\prime}} \leq \frac{f\left(\omega_{\widetilde{S}_{2} \cup Q}^{\prime}\right)-z_{Q}}{\omega_{\widetilde{S}_{2}}^{\prime}}
$$


for all $\varnothing \neq \widetilde{S}_{1} \subseteq \widetilde{S}_{2} \subseteq N \backslash \widetilde{R}$. Let $R \in \mathscr{D}_{S^{*}}$, with $|R|=k+1$, that is $R=\left\{j_{1}, j_{2}, \ldots, j_{k}, j_{k+1}\right\}$ where $\theta=\left(j_{1}, j_{2}, \ldots, j_{k}, j_{k+1}\right)$ is the ordering in which the inequalities required to be in the set $\mathscr{D}_{S^{*}}$ are satisfied. Let us remark that the coalition $R \backslash\left\{j_{k+1}\right\}$ is also in $\mathscr{D}_{S^{*}}$.

We have to prove (14) for all coalitions $\varnothing \neq S_{1} \subseteq S_{2} \subseteq N \backslash R$ and coalition $Q \subseteq R=$ $\left\{j_{1}, j_{2}, \ldots, j_{k}, j_{k+1}\right\}$. To this aim consider two cases:

Case 1.- Coalition $Q \subseteq R$ satisfies $j_{k+1} \notin Q$. In this case (14) holds simply by applying (15) to $\widetilde{R}=R \backslash\left\{j_{k+1}\right\}$ and taking $\widetilde{S}_{1}=S_{1}$ and $\widetilde{S}_{2}=S_{2}$.

Case 2.- Coalition $Q \subseteq R$ satisfies $j_{k+1} \in Q$. Taking into account $\varnothing \neq S_{1} \subseteq S_{2} \subseteq N \backslash R$ we have,

$$
\begin{aligned}
& \frac{f\left(\omega_{S_{1} \cup Q}^{\prime}\right)-z_{Q}}{\omega_{S_{1}}^{\prime}}
\end{aligned}
$$

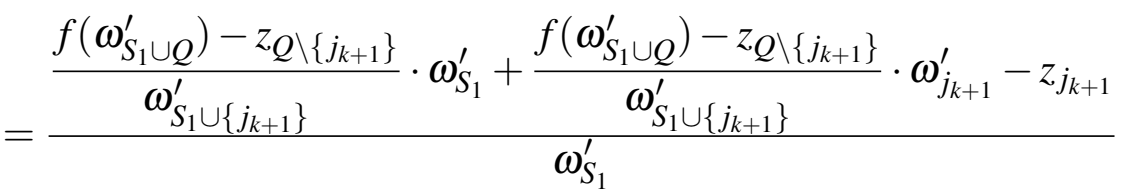

$$
\begin{aligned}
& =\frac{f\left(\omega_{S_{1} \cup Q}^{\prime}\right)-z_{Q \backslash\left\{j_{k+1}\right\}}}{\omega_{S_{1} \cup\left\{j_{k+1}\right\}}^{\prime}}+\frac{\frac{f\left(\omega_{S_{1} \cup Q}^{\prime}\right)-z_{Q \backslash\left\{j_{k+1}\right\}}}{\omega_{S_{1} \cup\left\{j_{k+1}\right\}}^{\prime} \omega_{j_{k+1}}^{\prime}-z_{j_{k+1}}}}{\omega_{S_{1}}^{\prime}} \\
& =\frac{f\left(\omega_{\left(S_{1} \cup\left\{j_{k+1}\right\}\right) \cup\left(Q \backslash\left\{j_{k+1}\right\}\right)}^{\prime}\right)-z_{Q \backslash\left\{j_{k+1}\right\}}}{\omega_{S_{1} \cup\left\{j_{k+1}\right\}}^{\prime}}+ \\
& \frac{\frac{f\left(\omega_{\left(S_{1} \cup\left\{j_{k+1}\right\}\right) \cup\left(Q \backslash\left\{j_{k+1}\right\}\right)}^{\prime}\right)-z_{Q \backslash\left\{j_{k+1}\right\}}}{\left.\omega_{S_{1} \cup\left\{j_{k+1}\right\}}^{\prime}\right\}} \omega_{j_{k+1}}^{\prime}-z_{j_{k+1}}}{\omega_{S_{1}}^{\prime}} \\
& \leq \frac{f\left(\omega_{\left(S_{2} \cup\left\{j_{k+1}\right\}\right) \cup\left(Q \backslash\left\{j_{k+1}\right\}\right)}^{\prime}\right)-z_{Q \backslash\left\{j_{k+1}\right\}}}{\omega_{S_{2} \cup\left\{j_{k+1}\right\}}^{\prime}}+ \\
& \frac{\frac{f\left(\omega_{\left(S_{2} \cup\left\{j_{k+1}\right\}\right) \cup\left(Q \backslash\left\{j_{k+1}\right\}\right)}^{\prime}\right)-z_{Q \backslash\left\{j_{k+1}\right\}} \cup \omega_{j_{k+1}}^{\prime}-z_{j_{k+1}}}{\omega_{S_{2} \cup\left\{j_{k+1}\right\}}^{\prime}}}{\omega_{S_{1}}^{\prime}} \\
& \leq \frac{f\left(\omega_{S_{2} \cup Q}^{\prime}\right)-z_{Q \backslash\left\{j_{k+1}\right\}}}{\omega_{S_{2} \cup\left\{j_{k+1}\right\}}^{\prime}}+\frac{\frac{f\left(\omega_{S_{2} \cup Q}^{\prime}\right)-z_{Q \backslash\left\{j_{k+1}\right\}}}{\omega_{S_{2} \cup\left\{j_{k+1}\right\}}^{\prime} \omega_{j_{k+1}}^{\prime}-z_{j_{k+1}}}}{\omega_{S_{2}}^{\prime}}=\frac{f\left(\omega_{S_{2} \cup Q}^{\prime}\right)-z_{Q}}{\omega_{S_{2}}^{\prime}},
\end{aligned}
$$

where the first inequality comes from (15) applied to $\widetilde{R}=\left\{j_{1}, \ldots, j_{k}\right\}, \widetilde{S}_{1}=S_{1} \cup\left\{j_{k+1}\right\}$ and $\widetilde{S}_{2}=S_{2} \cup\left\{j_{k+1}\right\}$ and the second inequality follows since it can be proved that

$$
\frac{f\left(\omega_{S_{2} \cup Q}^{\prime}\right)-z_{Q \backslash\left\{j_{k+1}\right\}}}{\omega_{S_{2} \cup\left\{j_{k+1}\right\}}^{\prime}} \cdot \omega_{j_{k+1}}^{\prime}-z_{j_{k+1}} \leq 0 .
$$


Indeed, being $R=\left\{j_{1}, \ldots, j_{k}, j_{k+1}\right\} \in \mathscr{D}_{S^{*}}$, this inequality follows since

$$
\begin{aligned}
z_{j_{k+1}} & \geq \max _{\widetilde{Q} \subseteq\left\{j_{1}, \ldots, j_{k}\right\}}\left\{\frac{f\left(\omega_{\left(N \backslash\left\{j_{1}, \ldots, j_{k}\right\}\right) \cup \widetilde{Q}}^{\prime}\right)-z_{\widetilde{Q}}}{\left.\omega_{N \backslash\left\{j_{1}, \ldots, j_{k}\right\}}^{\prime}\right\}}\right\} \omega_{j_{k+1}}^{\prime} \\
& \geq \frac{f\left(\omega_{\left(N \backslash\left\{j_{1}, \ldots, j_{k}\right\}\right) \cup\left(Q \backslash\left\{j_{k+1}\right\}\right)}^{\prime}\right)-z_{Q \backslash\left\{j_{k+1}\right\}}}{\omega_{N \backslash\left\{j_{1}, \ldots, j_{k}\right\}}^{\prime}} \cdot \omega_{j_{k+1}}^{\prime} \\
& \geq \frac{f\left(\omega_{\left(S_{2} \cup\left\{j_{k+1}\right\}\right) \cup\left(Q \backslash\left\{j_{k+1}\right\}\right)}^{\prime}\right)-z_{Q \backslash\left\{j_{k+1}\right\}}}{\omega_{S_{2} \cup\left\{j_{k+1}\right\}}^{\prime}} \cdot \omega_{j_{k+1}}^{\prime}, \\
& \geq \frac{f\left(\omega_{S_{2} \cup Q}^{\prime}\right)-z_{Q \backslash\left\{j_{k+1}\right\}}}{\left.\omega_{S_{2} \cup\left\{j_{k+1}\right\}}^{\prime}\right\}} \omega_{j_{k+1}}^{\prime},
\end{aligned}
$$

where the third inequality follows from (15) by taking $\widetilde{R}=R \backslash\left\{j_{k+1}\right\}=\left\{j_{1}, \ldots, j_{k}\right\}$, $\widetilde{S}_{1}=S_{2} \cup\left\{j_{k+1}\right\}$ and $\widetilde{S}_{2}=N \backslash\left\{j_{1}, \ldots, j_{k}\right\}$. Therefore, the claim is proved.

\section{References}

1. Anand K, Aron R (2003) Group buying on the web: a comparison of price discovery mechanisms. Manage Sci 49:1546-1562

2. Borm P, De Waegenaere A, Rafels C, Suijs J, Tijs S (2001) Cooperation in capital deposits. OR-Spektrum 23:265-281

3. Bourreau M, Cambini C, Hoernig S (2012) Ex-ante regulation and co-investment in the transition to next generation access. Telecommunications Policy 36:399-406

4. Bourreau M, Cambini C, Hoernig S (2018) Cooperative investment, access and uncertainty. Int $\mathrm{J}$ of Industrial Organization 56:78-106

5. Casajus C, Huettner F (2014) Weakly monotonic solutions for cooperative games. J Econ Th 154:162-172

6. Corcho P, Ferreira JL (2003) Generalized externality games. Th Decision 54:163-184

7. De Waegenaere A, Suijs J, Tijs S (2005) Stable profit sharing in cooperative investment. ORSpektrum 27:85-93

8. Di Luca C, Izquierdo JM, Rafels C (2013) Remarks on the proportional distribution in increasing return to scale problems. Econ Bull 33:2938-2947

9. Driessen T (1988) Coperative games, solutions and applications. Theory and Decision Library Series C, vol 3, Springer-Verlag, Berlin

10. Friedman E (2004) Strong monotonicity in surplus sharing. Econ Th 23:643-658

11. Gulick G, Borm P, De Waegenaere A, Hendrinckx R (2010) Deposit games with reinvestment. Eur J Oper Res 200:788-799 
12. Hong DH (2016) Core on Fuzzy Interval Cooperative Games. Applied Math Sci 10(18):887898

13. Izquierdo JM, Rafels C (1996) A generalization of the bankruptcy game: financial cooperative games, Working Paper E96/09, University of Barcelona

14. Izquierdo JM, Rafels C (2001) Average monotonic cooperative games. Games Econ Behav 36:174-192

15. Khavul S, Deeds D (2016) The evolution of initial co-investment syndications in an emerging venture capital market. J Int Management 22:280-293

16. Klement EP, Manzi M, Mesiar R (2011) Ultramodular aggregation functions. Inf Sci 18:41014111

17. Kogan K, Tapiero CS (2012) Coordination of co-investments in supply chain infrastructure. J Intell Manuf 23:24712475

18. Liu X, Liu J, Lic C (2013) Average monotonic cooperative fuzzy games. Fuzzy Sets and Systems 231:95107

19. Liu J, Tian HY (2014) Existence of fuzzy cores and generalizations of the KKMS theorem J Math Econ 52:148-152

20. Sagara N, Vlach M (2011) A new class of convex games on -algebras and the optimal partitioning of measurable spaces. Int J Game Theory 40:617-630

21. Schaarsberg M, Borm P, Hamers H, Reijnierse H (2013) Game theoretic analysis of maximum cooperative purchasing situations. Nav Res Log 16:607-624

22. Telser LG (1994) The usefulness of core theory in economics. J Econ Perspect 8:151-164

23. Tykvová T (2018) Venture capital and private equity financing: an overview of recent literature and an agenda for future research. J Bus Econ 88:325-362 